\title{
Preparation of Cholesteryl-Modified Aminated Pullulan Nanoparticles to Evaluate Nanoparticle of Hydrophobic Degree on Drug Release and Cytotoxicity
}

\author{
Huabing Yuan $\mathbb{D},{ }^{1,2}$ Wu Zhong, ${ }^{2}$ Rong Wang $\mathbb{D},{ }^{2}$ Ping Zhou, ${ }^{2}$ Yu Nie, ${ }^{2}$ Wei Hu, ${ }^{2}$ \\ Xiaojun Tao $\mathbb{D}^{2}{ }^{2}$ and Ping Yang $\mathbb{B}^{1}$ \\ ${ }^{1}$ The First People's Hospital of Tianmen in Hubei Province, China \\ ${ }^{2}$ Hubei Province Key Laboratory of Occupational Hazard Identification and Control, \\ Wuhan University of Science and Technology, China \\ Correspondence should be addressed to Xiaojun Tao; xiaojtao@126.com and Ping Yang; pingyang_1963@126.com
}

Received 6 August 2019; Revised 10 November 2019; Accepted 21 December 2019; Published 17 January 2020

Academic Editor: Renyun Zhang

Copyright (c) 2020 Huabing Yuan et al. This is an open access article distributed under the Creative Commons Attribution License, which permits unrestricted use, distribution, and reproduction in any medium, provided the original work is properly cited.

\begin{abstract}
The formation of nanoparticles (NPs) and surface properties such as size and charge are affected by the amphiphilic property of polymer, which is vital for evaluating their function. Here, we synthesized cholesteryl-modified aminated pullulan polymers (CHPNs) with different amounts of cholesterol succinate (CHS). We characterized the three hydrophobically modified polymers $\left(\mathrm{CHPN}_{1}, \mathrm{CHPN}_{2}\right.$, and $\left.\mathrm{CHPN}_{3}\right)\left(\mathrm{CHS}: \mathrm{Pu}-\mathrm{NH}_{2}=1 / 5,2 / 5,3 / 5\right)$ by Fourier transform infrared spectrometry. Dynamic light scattering (DLS) was used to measure particle size and zeta potential of CHPN NPs. The particle sizes of the three NPs CHPN ${ }_{1}$, $\mathrm{CHPN}_{2}$, and $\mathrm{CHPN}_{3}$ were 178.0, 144.4, and $97.8 \mathrm{~nm}$, respectively. The particle size was related to the cholesteryl substitution of polymers to a certain extent: the stronger the hydrophobicity, the smaller the particle size. In $48 \mathrm{~h}$, the drug release for $\mathrm{CHPN}_{3}$ and $\mathrm{CHPN}_{1}$ NPs was $57.8 \%$ and $72.7 \%$. Thus, the NPs showed good sustained drug release: the greater the degree of hydrophobic substitution, the better the sustained release. The cytotoxicity findings were reversed: $\mathrm{CHPN}_{1} \mathrm{NPs}_{\text {, with low }}$ hydrophobic substitution, showed the best inhibition of Lewis lung cancer cells.
\end{abstract}

\section{Introduction}

Amphiphilic polymers can spontaneously form shell-core structure nanoparticles (NPs) by self-assembly in the aqueous phase [1]. As an excellent drug carrier, NPs have been widely used in the field of antitumor drug delivery $[2,3]$. Self-assembly of polymers to form NPs is aimed at maintaining a stable structure and morphology by hydrophobic interaction between hydrophobic groups and hydrogen bonding, electrostatic interaction, etc. $[4,5]$. The hydrophobic interaction between the hydrophobic groups always has a leading role in the formation of NPs [6]. Therefore, many studies of polymer synthesis have examined the formation properties and function of NPs by hydrophobic substitution. Some of these studies show that changing the grafting density of the hydrophobic-substituted base can change the size, shape, elasticity, solubility, and stability of NPs [7-10].
The effect of hydrophobic substitution degree on some properties of NPs will affect the function of the NPs. The greater the degree of hydrophobic substitution, the smaller the particle size of self-assembled NPs [10]. The size of NPs plays a decisive role in the accuracy of their passive targeted delivery of anticancer drugs: 50 to $200 \mathrm{~nm}$ NPs can make better use of the high permeability of blood vessels near the tumor and enhanced permeability retention (EPR) effect of passive targeting of tumor sites [11]; therefore, the effect of hydrophobic substitution on the size of NPs is of great significance. The particle size is also associated with body immunity [12]; indeed, with about $100 \mathrm{~nm}$ particle size, phagocytosis of macrophages can be avoided [13, 14]. In addition, the greater the hydrophobic substitution, the more stable the particle and the longer the circulation in the body [15]; however, such NPs have lower deformability and more difficulty entering tumor cells than flexible 
hydrophobic particles [16]. Hydrophobic substitution also affects the release of carrier NPs and even the activity and effect of the loaded drug [17]. The hydrophobic part of NPs determines the immune response. Also, cytotoxicity is associated with the degree of hydrophobic substitution of NPs [18]. Therefore, the hydrophobic substitution degree in constructing drug carrier NPs should be carefully controlled, and the important properties and functional changes of NPs caused by different hydrophobic substitutions need investigation.

Polysaccharides such as dextran, chitosan, and pullulan can be modified by hydrophobic groups such as long carbon chains or cholesterol groups to form amphiphilic polymers $[19,20]$. Pullulan polysaccharide is nontoxic, water-soluble, biocompatible, and easy to biodegrade and contains many active hydroxyl groups [21]. It is easy to connect hydrophobic groups by chemical modification such as esterification to form amphiphilic graft copolymers [22]. Previous study of cholesterol-modified pullulan polysaccharide showed that it has high loading capacity and a sustained-release effect [23]. The hydrophobicity of NPs can be changed by changing the substitution degree of cholesterol, which changes the size and drug loading and release of NPs [24]. However, because of the large surface area and high surface activity, NPs can easily agglomerate, which will have adverse effects [10, 25]. Because of electrostatic repulsion, charged NPs are not easily aggregated as compared with uncharged NPs. Cell membranes are negatively charged, so they have high affinity with positive substances that will be highly uptaken by cells. The amino group, a positively charged and hydrophilic group, can be modified on the surface of drug-loaded NPs to make them positive, thereby increasing the internalization in cells [26].

In this study, we synthesized amphiphilic polymers with different hydrophobic modifications, prepared blank NPs, and methotrexate- (MTX-) loaded NPs (CHMP NPs). To explore the effect of hydrophobic degree on the structure and function of NPs, we used dynamic light scattering (DLS) to observe the morphology, size, and potential of the assembled NPs as well as drug release and cytotoxicity of drug-loaded NPs in vitro.

\section{Materials and Methods}

2.1. Materials. Cholesterol and Boc-glycine were from Shanghai Ruiyong Biotechnology; pullulan, 4-dimethylaminoaniline (DMAP), 1-ethyl-(3-dimethylaminopropyl) carbodiimide salt, and acid salt (EDC) were from Aladdin Reagent (Shanghai); and succinic anhydride, dimethyl sulfoxide (DMSO), pyridine, and trifluoroacetic acid (TFA) were from Sinopharm Chemical Reagent. Double distilled water was homemade, and reagents were of analytical grade. Mouse Lewis lung carcinoma (LLC) cells were purchased from Shanghai GeneChem Co., LTD. High-glucose DMEM, phosphatebuffered saline (PBS), and fetal calf serum (10099-141) were from Gibco.

\subsection{Synthesis of CHPN Polymer (Figure 1)}

2.2.1. Synthesis of Succinic Anhydride Cholesterol (CHS). NIn brief, $2 \mathrm{~g}$ cholesterol, and $1 \mathrm{~g}$ succinic acid were weighed into a round-bottom flask, and an appropriate amount of pyridine was added to dissolve them; the reaction was stirred for $48 \mathrm{~h}$ in an oil bath at $50^{\circ} \mathrm{C}$. The reacted liquid was then poured into $1000 \mathrm{~mL}$ of $0^{\circ} \mathrm{C}$ double distilled water. Hydrochloric acid was added to adjust the $\mathrm{pH}$ to 4 , and the beaker was chilled for $2 \mathrm{~h}$ and suction-filtered. The white solid was dissolved in $60 \mathrm{~mL}$ solution (ethanol: ethyl acetate 1:1), and succinic acid (CHS) was crystallized.

2.2.2. Synthesis of Aminated Pullulan ( $\left.\mathrm{Pu}-\mathrm{NH}_{2}\right)$. In brief, $10 \mathrm{~g}$ pullulan and $5 \mathrm{~g}$ Boc-glycine $(0.03 \mathrm{~mol})$ were added to $3.7 \mathrm{~g}$ DMAP $(0.03 \mathrm{~mol})$, dissolved in $200 \mathrm{~mL}$ dehydrated DMSO, and stirred at $50^{\circ} \mathrm{C}$ for 2 days; then, $30 \mathrm{~mL}$ TFA was added for $2 \mathrm{~h}$ incubation. After removing Boc-glycine, the mixture was added to $800 \mathrm{~mL}$ absolute ethanol and suction-filtered. The obtained solid was dissolved in water, filtered, and then dialyzed in a dialysis bag for $12 \mathrm{~h}$ and lyophilized with a freeze dryer to obtain a $\mathrm{Pu}-\mathrm{NH}_{2}$ solid product.

2.2.3. Synthesis of Different Hydrophobically Modified Aminated Pullulan Polymers (CHPNs). Three similar reaction systems were selected, with $0.56 \mathrm{~g} \mathrm{Pu}-\mathrm{NH}_{2}$ dissolved in $10 \mathrm{~mL}$ DMSO. According to the molar ratio of $\mathrm{CHS}$ and sugar units $1 / 5,2 / 5$, and $3 / 5$, namely, $0.2,0.4$, and $0.6 \mathrm{~g}$ CHS; $0.18 \mathrm{~g}$ DMAP ( $1.5 \mathrm{mmol})$; and $0.35 \mathrm{~g}$ EDC ( $1.8 \mathrm{mmol})$, the CHS was dissolved in $10 \mathrm{~mL}$ DMSO and stirred at room temperature to activate $\mathrm{CHS}$, and the activated reaction liquid was dropped into the DMSO solution of amino pullulan polysaccharide to synthesize $\mathrm{CHPN}_{1}, \mathrm{CHPN}_{2}$, and $\mathrm{CHPN}_{3}$. In short, the content was mixed at $50^{\circ} \mathrm{C}$ with oil bath mixing and a heating reaction for $48 \mathrm{~h}$. The reaction was stopped and cooled to room temperature; then, the reaction liquid was dropped into an appropriate amount of anhydrous ethanol, continuously stirred to precipitate the white precipitate, extracted, and filtered; then, an appropriate amount of anhydrous ethanol, tetrahydrofuran, and ether washing products was added, at $50^{\circ} \mathrm{C}$ dry under standby treatment, to produce a light yellow solid.

2.2.4. Characterization of Polymers by Fourier Transform Infrared (FTIR) and Nuclear Magnetic Resonance (NMR). A small amount of solid succinic anhydride cholesterol, amino pullulan polysaccharide, and different CHPNs as well as infrared dry potassium bromide powder was mixed under infrared light and pressed into transparent sample potassium bromide tablets. The infrared spectra of samples were obtained by scanning in the range of $500 \sim 4000 \mathrm{~cm}^{-1}$. A small amount of solid succinic anhydride cholesterol ester, amino pullulan polysaccharide, and different CHPNs was dissolved in deuterium DMSO and analyzed by NMR. The degree of substitution of CHS was determined on the basis of the $\alpha-1,4$ and $\alpha-1,6$ glycosidic bonds and the area under the methylene peak [24]:

$$
\mathrm{DS}=\frac{A_{\delta 2.53}}{4\left(A_{\delta 5.05}+A_{\delta 4.68}\right)} \times 100 \%
$$

2.2.5. DSC and XRD of Active Pharmaceutical Ingredient (API) and Polymer. The differential scanning calorimetry 

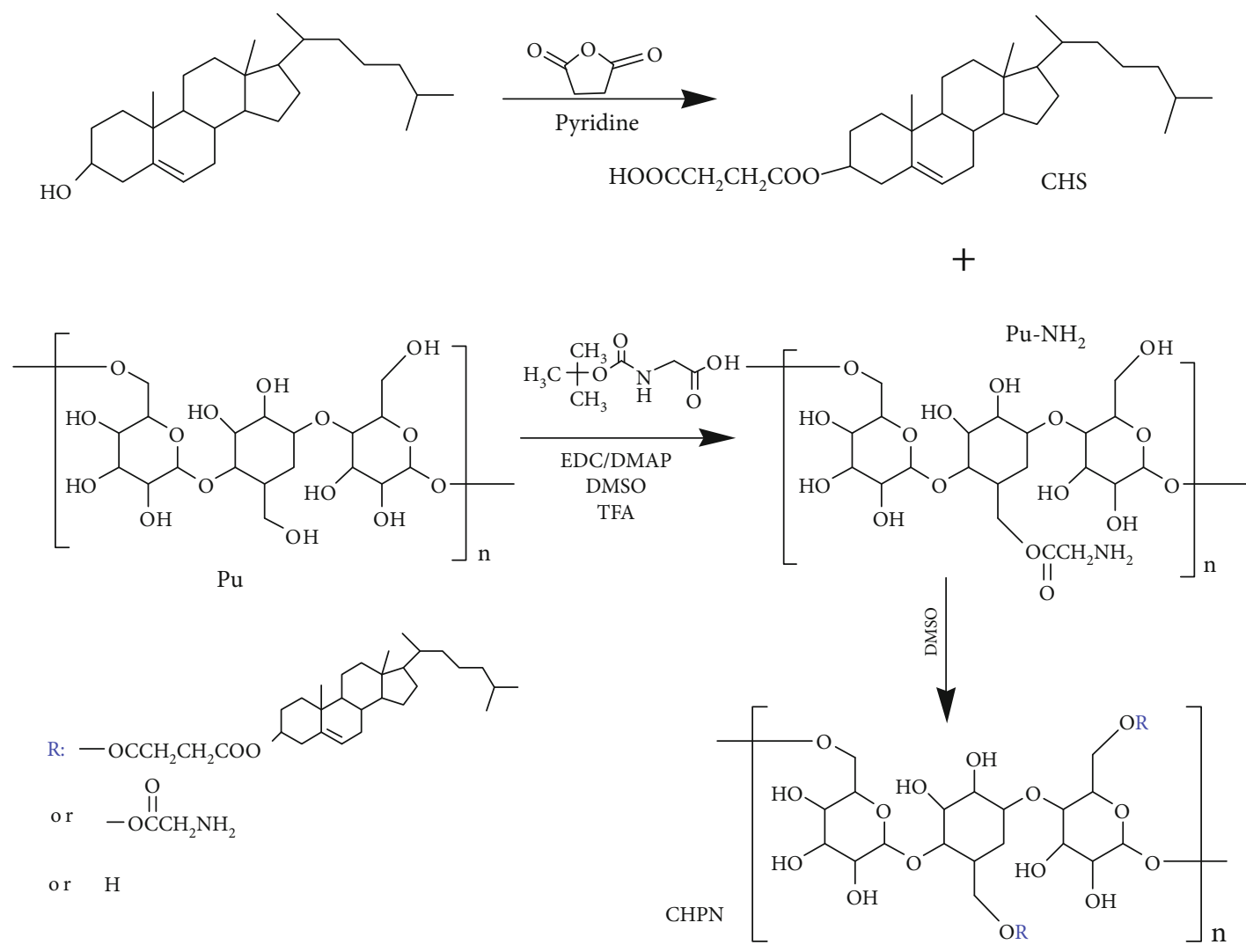

Figure 1: Chemical synthesis of CHPN polymer.

(DSC) analysis was performed using a Differential Scanning Calorimeter (DSC200F3, NETZSCH, Germany); samples were heated from 10 to $200^{\circ} \mathrm{C}$ at a heating rate of $10^{\circ} \mathrm{C} / \mathrm{min}$ under nitrogen atmosphere. X-ray diffraction (XRD) was performed using a diffractometer (D8 Discover, Bruker AXS, Germany), with an interval $0.02 \mathrm{~s}$ in the $2 \theta$ range of $10^{\circ}-90^{\circ}$.

2.3. Preparation of Blank and Drug-Loaded NPs. NPs were prepared by dialysis. Specifically, $0.3 \mathrm{~g}$ amino-modified CHPNs, $\mathrm{CHPN}_{1}, \mathrm{CHPN}_{2}$, and $\mathrm{CHPN}_{3}$, were dissolved in DMSO, stirred at room temperature until they completely dissolved, and then put into dialysis bags $(7 \mathrm{kDa})$. After dialysis for $48 \mathrm{~h}$ with double distilled water, DMSO was removed to obtain hydrophobically modified amino pullulan polysaccharide NPs, $\mathrm{CHPN}_{1}, \mathrm{CHPN}_{2}$, and $\mathrm{CHPN}_{3}$ NPs. Drugloading NPs were also formed by the dialysis method, taking $\mathrm{CHPN}_{1}, \mathrm{CHPN}_{2}$, and $\mathrm{CHPN}_{3}, 0.3 \mathrm{~g}$ each, stirring them until completely dissolved, adding DMSO, then adding $2 \mathrm{mg}$ of the model drug MTX dissolved in $2 \mathrm{~mL}$ of DMSO, and dropping them into the above solution, by using the dialysis bag $(7 \mathrm{kDa}$ intercept molecular weight) for dialysis in double distilled water for $24 \mathrm{~h}$ to remove organic solvent and free drug MTX, then to obtain $\mathrm{CHMPN}_{1}, \mathrm{CHMPN}_{2}$, and $\mathrm{CHMPN}_{3} \mathrm{NPs}_{\text {. The }}$ preparation of drug-loading NPs was in the dark at all times.

\subsection{Characterization of Blank and Drug-Loaded CHPN NPs}

2.4.1. Dynamic Light Scattering. The prepared blank and drug-loaded NPs were placed into colorimetric cups, then placed into the DLS granulometer (DLS, Zetasizer $3000 \mathrm{HS}$, Malvern Instruments, Malvern, UK). Each sample was tested three times, $1 \mathrm{~min} /$ time. The test conditions were argon ion laser, wavelength $658 \mathrm{~nm}$, temperature $25 \pm 0.1$ degrees, and DLS angle $90^{\circ}$. The zeta potential was determined at the same time. The operating conditions were $11.4 \mathrm{v} / \mathrm{cm}, 13.0 \mathrm{~mA}$, and $25^{\circ} \mathrm{C}$. The sample solvent was diluted with distilled water.

2.4.2. Transmission Electron Microscopy (TEM) and Scanning Electron Microscope (SEM). Blank CHPN NPs $\left(\mathrm{CHPN}_{1} \mathrm{NPs}\right)$ with the same substitution and drug-loaded NPs $\left(\mathrm{CHPN}_{1}\right.$ NPs) were dropped on copper mesh coated with carbon support film, dyed with $2 \%$ phosphorus-uric acid, and morphology was observed by TEM after natural drying. The SEM images of CHPN NPs and CHMPN NPs were obtained using S-4800 instrument (Hitachi Ltd.) with an accelerating voltage of $10.0 \mathrm{kV}$.

2.5. Drug Loading and Release In Vitro. An amount of $10 \mathrm{mg}$ drug-loaded NPs was accurately weighed, dispersed in $5 \mathrm{~mL}$ of $10 \mathrm{mmol} / \mathrm{L}$ phosphate buffer solution, sonicated for $10 \mathrm{~min}$, and filtered through a $0.2 \mu \mathrm{m}$ microporous membrane, and the filtrate was topped up to $10 \mathrm{~mL}$. An amount of $2 \mathrm{~mL}$ solution was pipetted into a cuvette, and absorbance was measured at $303 \mathrm{~nm}$ by using a microplate spectrophotometer (UV-384 plus, Molecular Devices, Thermo Fisher Scientific, Waltham, MA, USA), with reference to MTX standards. The curve was used to determine the concentration of MTX in the solution, and drug 
loading (LC) of different nanocarriers of MTX was calculated as follows:

$$
\mathrm{LC} \%=\frac{\text { amount of drug in the NP }}{\text { NP weight }} \times 100 \%
$$

Drug release was measured by the dialysis method. Briefly, $5 \mathrm{mg}$ drug-loaded NPs were dispersed in $10 \mathrm{~mL}$ phosphate buffer $\left(\mathrm{pH} 7.4\right.$, temperature $\left.37.5^{\circ} \mathrm{C}\right)$ and loaded into a dialysis bag $\left(M_{W}=8-12 \mathrm{kDa}\right)$ and separated at $25 \mathrm{~mL}, \mathrm{pH}$ 7.4. Dialysis was carried out in PBS (release medium) at $37^{\circ} \mathrm{C}$ and shaking at $80 \mathrm{rpm}$. Then, $2 \mathrm{~mL}$ release medium was collected for sampling and replaced with an equal volume of fresh solution at predetermined time intervals $\left(T_{n}=0,0.5,1,2,4,8,12,24,48,72 \mathrm{~h}\right)$. The absorbance of MTX in the solution was measured by using a microplate spectrophotometer, and three samples were taken from each group to determine the released MTX. The percentage of drug release $(Q \%)$ was calculated as follows:

$$
\mathrm{Q} \%=\frac{\left(C_{n} \times V+V_{n} \sum_{t=0}^{n} C_{i}\right)}{\left(W_{\mathrm{NP}} \times \mathrm{LC} \%\right)}
$$

where $W$ is the NP weight, $C_{n}$ is the sample concentration at $T_{n}, V$ is the total volume of release medium, $V_{n}$ is the sample volume $(2 \mathrm{~mL})$, and $C_{i}$ is the sample concentration at $T_{i}$ ( $i=0,0.5,1, \cdots, n$ hours, both $V_{0}$ and $C_{0}$ are equal to zero).

2.6. Cell Culture. Mouse Lewis lung carcinoma (LLC) cells were cultured with $13 \%$ fetal bovine serum, $1 \%$ double antibody (penicillin, streptomycin), inoculated in a $25 \mathrm{~cm}^{2}$ culture flask, and cultured in a $37^{\circ} \mathrm{C}$ incubator at $5 \% \mathrm{CO}_{2}$ for amplification. The experimental cells were all derived from logarithmic growth-phase cells.

2.7. In Vitro Cytotoxicity. An amount of 3000 mouse lung cancer LLC cells was placed per well in a 96-well plate. After cells attached, $\mathrm{CHMPN}_{1}, \mathrm{CHMPN}_{2}, \mathrm{CHMPN}_{3} \mathrm{NPs}$ and free MTX with the same MTX concentration were added. The concentrations were $10,20,30,40$, and $50 \mu \mathrm{g} / \mathrm{mL}$. After the drug was added for 24 or $48 \mathrm{~h}, 10 \mathrm{~mL}$ CCK- 8 reagent was added and incubated for $2 \mathrm{~h}$. Then, absorbance at $450 \mathrm{~nm}$ wavelength was detected by using an enzyme-labeling instrument. A group without the drug was a control, and a blank cell group was a control. The inhibition rate of different drug preparations for LCC cells was calculated as follows:

$$
\begin{aligned}
& \text { Inhibition rate }(\%) \\
& \quad=\frac{\mathrm{OD}(\text { experimental group })-\mathrm{OD}(\text { blank group })}{\mathrm{OD}(\text { control group })-\mathrm{OD}(\text { blank group })} \times 100 \% .
\end{aligned}
$$

2.8. Statistical Analysis. Statistical analysis was performed with origin 8.5 and GraphPad Prism 7. Every cell experimental treatment was repeated independently for at least three times, and all of the results were expressed as mean with $95 \%$ CI.

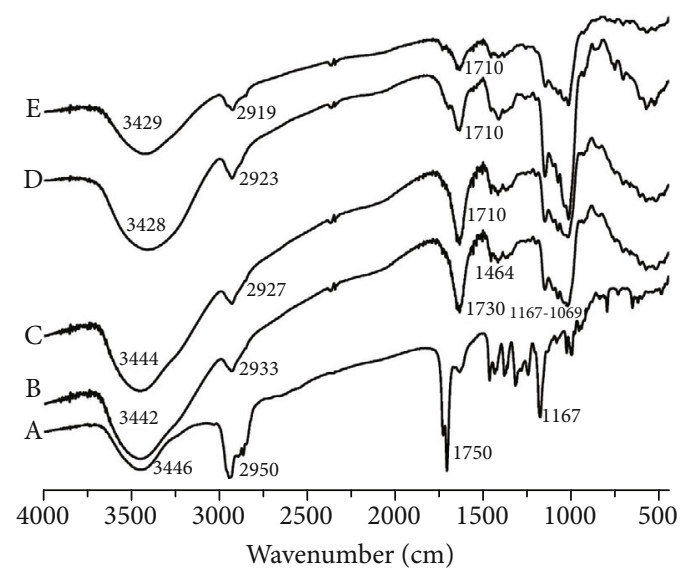

FIGURE 2: FTIR spectra for cholesterol succinate (CHS) (a), $\mathrm{Pu}-\mathrm{NH}_{2}$ (b), $\mathrm{CHPN}_{1}$ (c), $\mathrm{CHPN}_{2}$ (d), and $\mathrm{CHPN}_{3}$ (e).

\section{Result}

3.1. FTIR and ${ }^{1} H$ NMR Analysis. The synthesis of polymer $\mathrm{CHPN}$, esterified from CHS and $\mathrm{Pu}-\mathrm{NH}_{2}$, is in Figure 1. The structural characterization of the polymer was proved by FTIR and NMR analysis. The peak near $1167-1069 \mathrm{~cm}^{-1}$ is the C-N stretching vibration peak, the peak near $1500 \mathrm{~cm}^{-1}$ is the $\mathrm{N}-\mathrm{H}$ and $\mathrm{C}-\mathrm{N}$ coupling vibration peak, and the peak near $1730 \mathrm{~cm}^{-1}(\mathrm{C}=\mathrm{O}$ stretching vibration peak) proves the successful grafting of $\mathrm{NH}_{2}$ on pullulan (Figure 2(b)).

As compared with CHS, $\mathrm{Pu}-\mathrm{NH}_{2}$ and $\mathrm{CHPN}$ have stronger - $\mathrm{OH}$ characteristic peaks near $3450 \mathrm{~cm}^{-1}$ because they contain multiple hydroxyl groups, and - $\mathrm{NH}$ also has a characteristic peak near $3400 \mathrm{~cm}^{-1}$. The superimposition of the two enhances the absorption. However, CHS is attached to the polysaccharide hydroxyl group when CHPN is synthesized, and the strength of the hydroxyl group gradually decreases. The decrease is more pronounced with increasing amount of CHS because the number of hydroxyl groups decreases as ester bonds are formed between the two. The stretching vibration peaks of methyl and methylene were close to $2900 \mathrm{~cm}^{-1}$, but the absorption peaks of CHPN and CHS were significantly enhanced close to $2900 \mathrm{~cm}^{-1}$, and an obvious ester carbonyl absorption peak appeared close to1750-1710 $\mathrm{cm}^{-1}$. The CHS absorption peak at $1167 \mathrm{~cm}^{-1}$ represented a $\mathrm{C}-\mathrm{O}$ stretching vibration peak, and the strong and broad peaks of $\mathrm{Pu}-\mathrm{NH}_{2}$ and $\mathrm{CHPN}$ near this represented a C-O-C stretching vibration peak. Their fingerprint regions are approximately similar, indicating structural similarities.

The characteristic NMR spectra peaks for CHS are in Figure 3: $0.8-1.5 \mathrm{ppm}$ is the side chain $-\mathrm{CH}_{2}$ and ring $-\mathrm{CH}_{2}$, 2.5-3.5 ppm is the characteristic peak of $\mathrm{CH}_{2}\left(-\mathrm{CH}_{2} \mathrm{CO}\right)$ next to its ester bond, $4.3 \mathrm{ppm}$ is the characteristic peak of its double bond $-\mathrm{C}=\mathrm{CH}$, and for $\mathrm{Pu}-\mathrm{NH}_{2}, 1.0 \mathrm{ppm}$ is the alkyl hydrogen on the sugar ring. The characteristic peaks for $-\mathrm{OH}$ and $-\mathrm{CH}_{2} \mathrm{CO}$ are 3-4 ppm, and those for $-\mathrm{CH}_{2} \mathrm{CO}$ and $-\mathrm{OH}$ are $4.6-5.5 \mathrm{ppm}$. As compared with $\mathrm{CHS}$ and $\mathrm{Pu}-\mathrm{NH}_{2}$, both $\mathrm{CHPN}$ spectra combined the absorption characteristics of $\mathrm{CHS}$ and $\mathrm{Pu}-\mathrm{NH}_{2} \cdot \mathrm{CH}=\mathrm{CH}_{2}$ peaks of CHS were found near $4.3 \mathrm{ppm}$, and the unique $-\mathrm{CH}_{2} \mathrm{CO}$ 


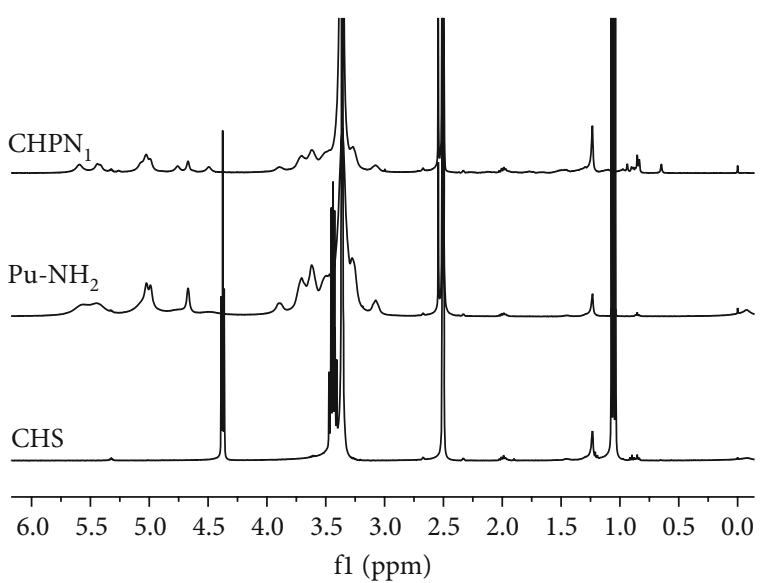

(a)

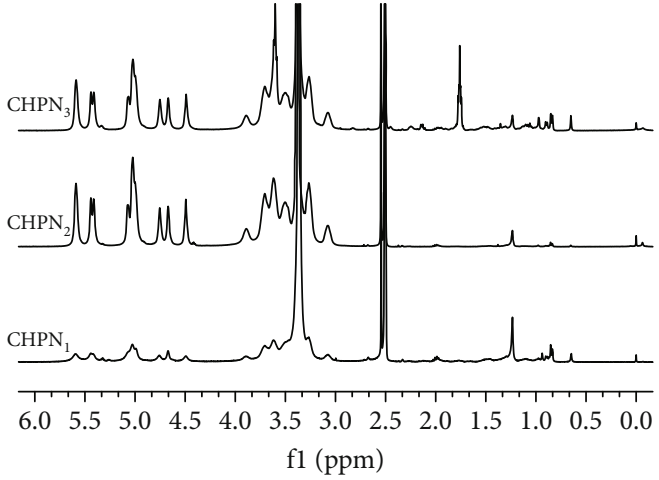

(b)

Figure 3: ${ }^{1} \mathrm{H}$ NMR spectra for CHS, Pu-NH${ }_{2}, \mathrm{CHPN}_{1}, \mathrm{CHPN}_{2}$, and $\mathrm{CHPN}_{3}$.

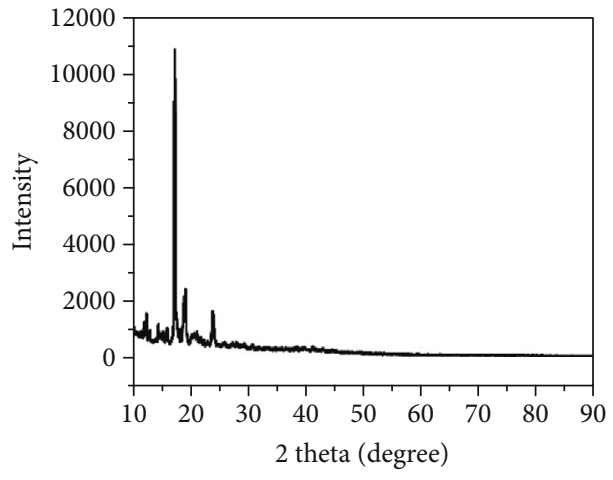

- CHS

(a)

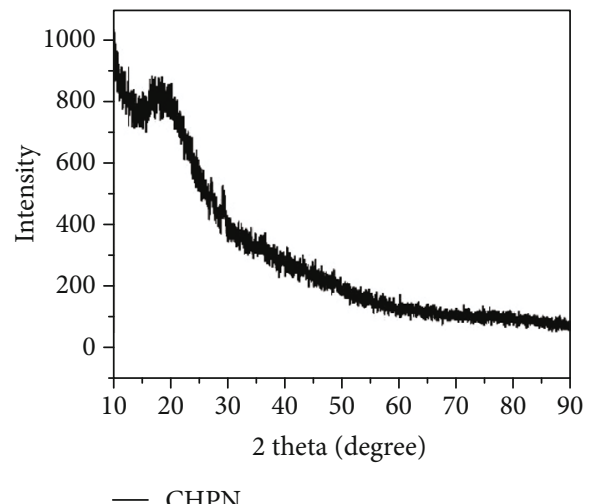

(c)

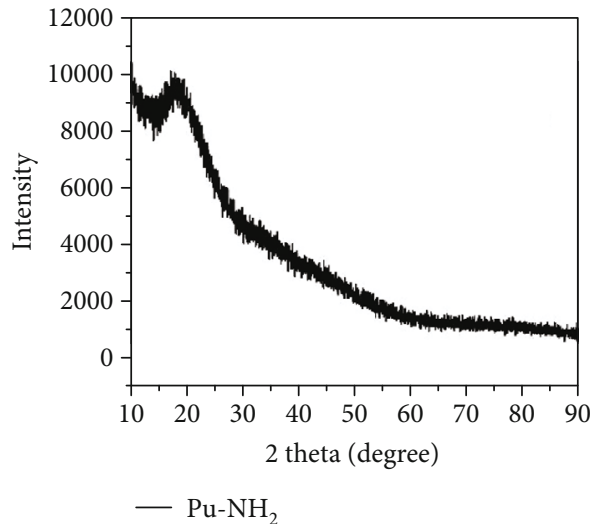

(b)

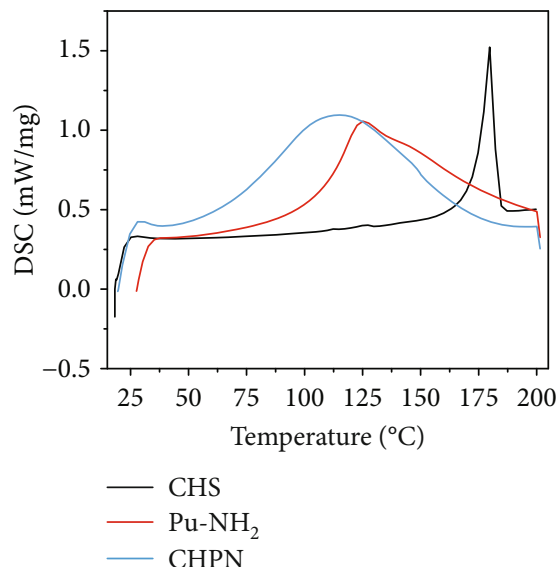

(d)

FIgURe 4: XRD (a-c) and standard DSC curves (d) of the APIs and polymer CHPN.

and $-\mathrm{OH}$ peaks for $\mathrm{Pu}-\mathrm{NH}_{2}$ were also found at 4.6-5.5 ppm. Thus, the successful synthesis of CHPN can be demonstrated by the chemical binding of cholesterol to the amino pullulan long chain. Calculated according to the formula, the cholesterol substitution degree of $\mathrm{CHPN}_{1}, \mathrm{CHPN}_{2}$, $\mathrm{CHPN}_{3}$ was $3.56 \%, 5.68 \%$ and $6.74 \%$, respectively.
3.2. DSC and XRD of CHS, Pu-NH , and Polymer. As shown in Figures 4(a)-4(c), CHS was crystalline at room temperature, while $\mathrm{Pu}-\mathrm{NH}_{2}$ and their polymer CHPN were not. The XRD indicated the change in crystallinity of CHS when it interacted with $\mathrm{Pu}-\mathrm{NH}_{2}$. And the DSC was shown in Figure $4(\mathrm{~d})$. The melting peak of $\mathrm{CHS}$ was at $179.5^{\circ} \mathrm{C}$ and 
TABLE 1: Size, polydispersity index (PDI), and zeta potential of CHPN NPs.

\begin{tabular}{lccc}
\hline NPs & Size $(\mathrm{nm})$ & PDI $(\mathrm{nm})$ & Zeta potential $(\mathrm{mV})$ \\
\hline $\mathrm{CHPN}_{1} \mathrm{NPs}$ & $178.0 \pm 4.2$ & $0.257 \pm 0.048$ & $4.29 \pm 0.94$ \\
$\mathrm{CHPN}_{2} \mathrm{NPs}$ & $144.4 \pm 3.6$ & $0.199 \pm 0.036$ & $3.39 \pm 0.77$ \\
$\mathrm{CHPN}_{3} \mathrm{NPs}$ & $97.8 \pm 2.2$ & $0.196 \pm 0.024$ & $2.56 \pm 0.18$ \\
\hline
\end{tabular}

$\mathrm{Pu}-\mathrm{NH}_{2}$ was at $125.9^{\circ} \mathrm{C}$. There was no endothermic peak of cholesterol in the polymer, suggesting its good compatibility.

3.3. Size Distribution, Potential, and Electron Microscopy Analysis of Blank NPs. The mean particle size and dispersion of $\mathrm{CHPN}_{1}, \mathrm{CHPN}_{2}$, and $\mathrm{CHPN}_{3}$ NPs were $178.0 \pm 4.2 \mathrm{~nm}$ and $0.257 \pm 0.048 \mathrm{~nm}, 144.4 \pm 3.6 \mathrm{~nm}$ and $0.199 \pm 0.036 \mathrm{~nm}$, and $97.8 \pm 2.2 \mathrm{~nm}$ and $0.196 \pm 0.024 \mathrm{~nm}$, respectively. Therefore, the particle size of NPs with different hydrophobic substitution degrees greatly differed, and the particle size of $\mathrm{CHS} / \mathrm{Pu}-\mathrm{NH}_{2}$ with high hydrophobic substitution was small. The dispersion of NPs also decreased with increasing hydrophobic substitution degree, which indicates that hydrophobic force plays an effective role in the stability of CHPN NPs; furthermore, hydrophobic action is the driving force of CHPN NP self-assembly. The mean zeta potentials for $\mathrm{CHPN}_{1}$, $\mathrm{CHPN}_{2}$, and $\mathrm{CHPN}_{3} \mathrm{NPs}$ were $4.29 \pm 0.94,3.39 \pm 0.77$, and $2.56 \pm 0.18 \mathrm{mV}$, respectively. (Table 1) The zeta potential difference was small, and potentials were positive. And the positive potential was smaller with higher degree of substitution. TEM and SEM showed CHPN NPs with a regular spherical structure.

3.4. Analysis of Drug-Loaded NPs. The mean size and dispersion of the drug MTX loadings of $\mathrm{CHPN}_{1}$ NPs, $\mathrm{CHPN}_{2} \mathrm{NPs}$, and $\mathrm{CHPN}_{3}$ NPs were $195.9 \pm 4.6 \mathrm{~nm}$ and $0.338 \pm 0.065$, $158.3 \pm 3.8 \mathrm{~nm}$ and $0.302 \pm 0.057$, and $123.2 \pm 2.9 \mathrm{~nm}$ and $0.246 \pm 0.046$, respectively. The zeta potentials were $3.46 \pm$ $0.27,3.16 \pm 0.62$, and $1.99 \pm 0.80 \mathrm{mV}$, respectively. The change rule for all three was the same as for the blank nanometer but decreased with hydrophobic substitution degree. $\mathrm{CHPN}_{1}$ and drug-loaded $\mathrm{CHPN}_{1}$ NPs had a regular spherical structure (Figures 5 and 6). The drug loading proportion for $\mathrm{CHPN}_{1}, \mathrm{CHPN}_{2}$, and $\mathrm{CHPN}_{3}$ NPs was $5.2 \pm 0.1 \%$, $6.7 \pm 0.4 \%$, and $8.6 \pm 0.3 \%$, respectively. NPs with high hydrophobic substitution degree had higher drug loading. Because of the negative charge of MTX [27], CHPN NPs were mainly affected by hydrophobic and electrostatic forces when carrying drugs, and the drug loading of CHPN NPs was positively related to the degree of hydrophobic substitution.

3.5. Drug Release In Vitro. As shown in Figure 7, the release of free drugs was relatively rapid, releasing $80.5 \%$ within $12 \mathrm{~h}$, while the drugs from NPs exhibited two phases of releasing. The two phases included a rapid release in the first $12 \mathrm{~h}$ and a sustained release followed. The rapid releasing was related to the surface-absorbed MTX, and the slowly sustained releasing was probably related to the encapsulated MTX. CHPN 3 NPs, with a high degree of hydrophobic sub- stitution, released $57.8 \%$ of drugs. $\mathrm{CHPN}_{2}$ NPs released $64.4 \%$ in $48 \mathrm{~h}$. $\mathrm{CHPN}_{1} \mathrm{NPs}$, with the lowest degree of substitution, released $72.7 \%$ within $48 \mathrm{~h}$. The release test indicated that NPs with high hydrophobic substitution had slower drug release; the higher the hydrophobic degree, the stronger the slow-release effect.

3.6. In Vitro Cytotoxicity of Drug-Loaded NPs. To confirm the inhibitory effect of MTX-loaded NPs on cancer cells and compare the function of different hydrophobically substituted NPs, we used mouse LLC cells, a lung carcinoma cell line, for cell viability testing. MTX is a broad-spectrum anticancer drug in clinical practice. Different hydrophobic NPs were used to encapsulate equal amounts of free MTX, for different preparations. The cell viability ratio with treatment for 24 and $48 \mathrm{~h}$ (Figures 8 and 9) was in the order of $\mathrm{CHMPN}_{1} \mathrm{NPs}^{2}<\mathrm{CHMPN}_{2} \mathrm{NPs}<\mathrm{MTX}<\mathrm{CHMPN}_{3}$ NPs. The cell viability of LLC cells under the inhibition of MTX, $\mathrm{CHMPN}_{1}, \mathrm{CHMPN}_{2}$, and $\mathrm{CHMPN}_{3}$ NPs for $24 \mathrm{~h}$ decreased to $61.8 \%, 47.1 \%, 57.2 \%$, and $65.7 \%$, respectively. The inhibition with $48 \mathrm{~h}$ decreased more, with a consistent cytotoxicity trend. The average $\mathrm{IC}_{50}$ for preparations are in Table 2. The cytotoxicity of $\mathrm{CHMPN}_{1}$ and $\mathrm{CHMPN}_{2} \mathrm{NPs}$ with low $\mathrm{CHS} / \mathrm{Pu}-\mathrm{NH}_{2}$ substitution was high, even better than that with the free drug MTX. CHMPN 3 NP toxicity in LLC cells was relatively less and slightly less than free drug.

\section{Discussion}

The formation of NPs and surface properties such as size and charge are affected by the amphiphilic property of polymer, which is vital for evaluating their function [28, 29]. Wei et al. found that the increase in hydrophobicity substitution reduces the size of hyaluronic acid-deoxycholate selfassembled NPs and increases their drug encapsulation efficiency [30]. Li et al. found that the cellular uptake increased in the bigger nanoparticles [31]. Sun et al. reported that insertion of hydrophobic octanethiol onto the surface of $2 \mathrm{~nm}$ zwitterionic luminescent glutathione-coated gold NPs enhanced their affinity for cell membranes and increased cell uptake by more than an order of magnitude [32]. These studies demonstrate the diversity and heterogeneity of hydrophobic-induced NP functions and provide new avenues for promoting cellular uptake by NPs. However, too much hydrophobic substitution results in lower blood compatibility [33], causing NPs to be unstable in the body; too little hydrophobic substitution will cause too-high critical aggregation concentration [34], and aggregation to form NPs will not be easy. Therefore, suitable hydrophobically substituted NPs must be screened by experiments to optimize drug delivery and increase the absorption of drugs by tumor cells.

In a previous study $[23,24]$, the drug loading of CHP NPs depended on the degree of cholesterol substitution in the polymer, and after reaching the critical concentration of aggregation to form NPs, the drug loading increased with increasing degree of substitution. Amino NPs had higher inhibitory activity in cancer cells than the two other kinds 


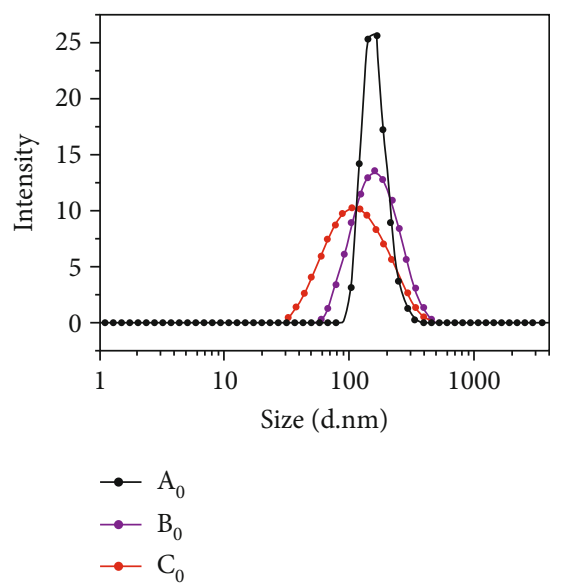

(a)

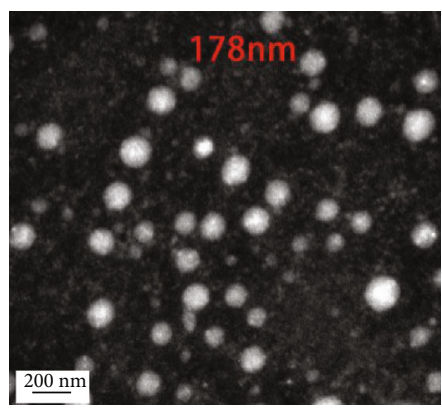

(c)

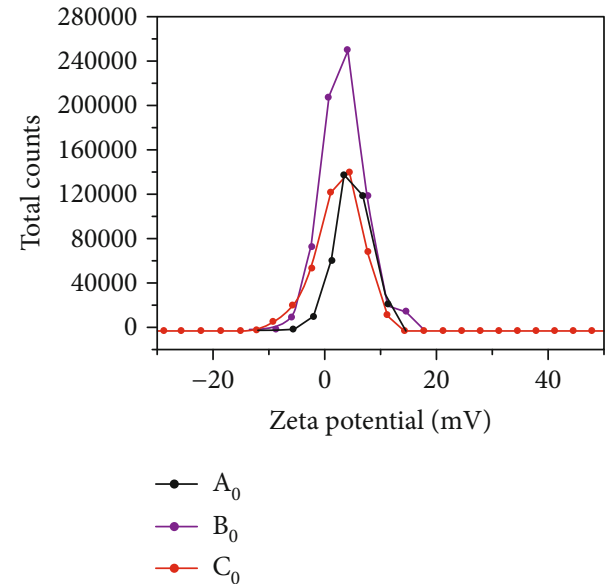

(b)

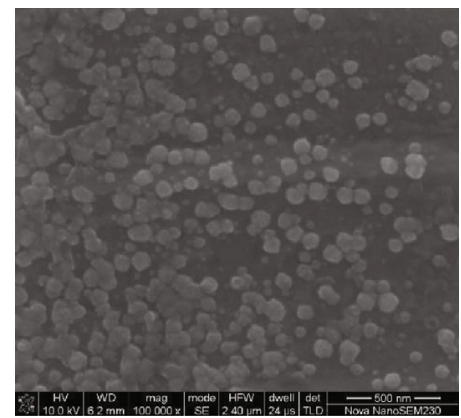

(d)

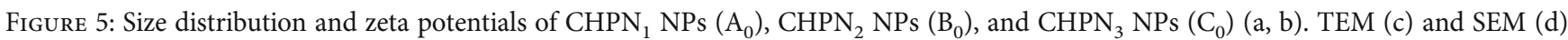
image of $\mathrm{CHPN}_{1}$ NPs.

of NPs by grafting cholesterol without modification and the carboxyl group [35].

In this study, we used Boc-glycine to graft pullulan polysaccharide to form a hydrophilic head, then combined it with cholesterol to form a hydrophobic tail by forming an ester bond to prepare the amphiphilic polymer, and then changed the amount of cholesterol to prepared NPs with different degrees of hydrophobic substitution. The size of different hydrophobic-substituted NPs differed, and particles with higher hydrophobic substitution were smaller. Thus, the self-assembly of the NPs was mainly driven by hydrophobic forces. Different hydrophobic substitutions of $\mathrm{CHS} / \mathrm{Pu}-\mathrm{NH}_{2}$ led to a slight difference in stability, but PDI showed that the stability of the three NPs was good in vitro.

The particle size of the NPs increased after drug loading, and the higher the degree of substitution for $\mathrm{CHS} / \mathrm{Pu}-\mathrm{NH}_{2}$, the greater the drug loading. The higher drug loading did not reverse the difference in particle size caused by hydrophobic substitution, which also indicated that the size of NPs controlled by hydrophobic substitution was relatively stable. All particle types were positively charged, which is related to the positive electrical properties of amino groups. The zeta potential decreased slightly with increasing $\mathrm{CHS} / \mathrm{Pu}-\mathrm{NH}_{2}$ substitution and further decreased after the acid drug MTX was coated. Because of the positive electrical properties of the amino group, the corresponding amino ratio decreased with a large substitution of $\mathrm{CHS} / \mathrm{Pu}-\mathrm{NH}_{2}$ or increased proportion of amino groups.

In vitro drug release studies showed that CHPN NPs could achieve the effect of slow release of drugs when used for drug delivery. With decreasing size, the drug sustainedrelease effect was significantly enhanced. This proves that the force affecting drug release was mainly hydrophobic rather than electrostatic. With the increase of hydrophobic force and the decrease of electrostatic attraction, drug release slowed down significantly.

In the in vitro cytotoxicity study, drug release to matrix caused the cell cytotoxicity, and the positive potential of NPs could also play an important role in the absorption by tumor cells; it increased the cellular uptake, then release of drugs in cells, and thus higher cytotoxicity. $\mathrm{CHPN}_{1} \mathrm{NPs}$ had the best effect in in vitro experiments, which had the lowest degree of hydrophobic substitution. The $\mathrm{CHPN}_{3} \mathrm{NPs}$ with the highest degree of substitution had the lowest cell toxicity, which may be due to its poor release and $\mathrm{NH}_{2}$ modification. $\mathrm{CHPN}_{1} / \mathrm{CHPN}_{2}$ seemed to be more toxic than free MTX by higher uptake. The less proportion of $\mathrm{NH}_{2}$ results in a smaller positive NP surface, and high hydrophobic substitution results in poor flexibility, then caused a decrease of drug release and cellular uptake, so $\mathrm{CHPN}_{3} \mathrm{NPs}$ cannot be so effective to tumor cells. 


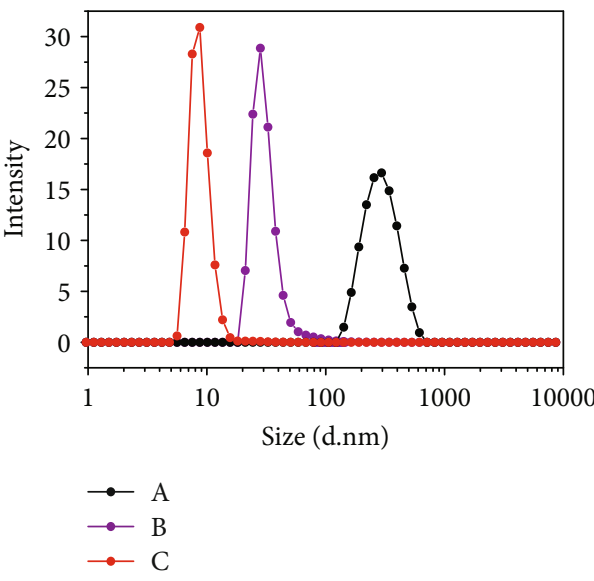

(a)

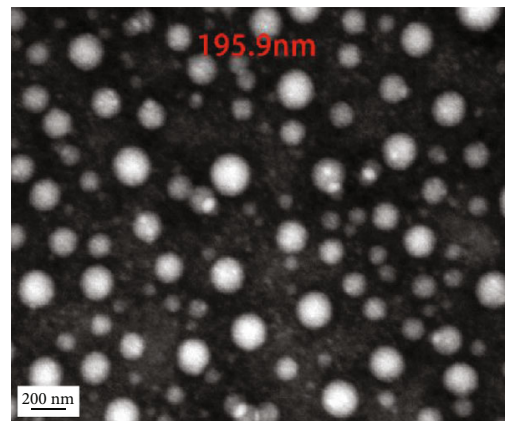

(c)

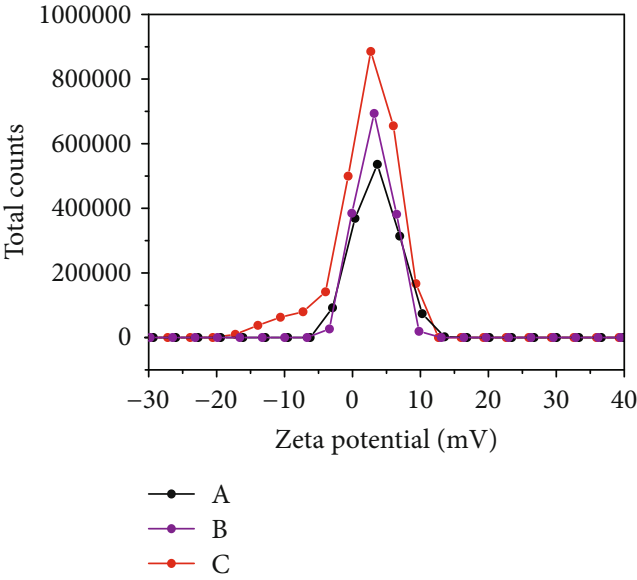

(b)

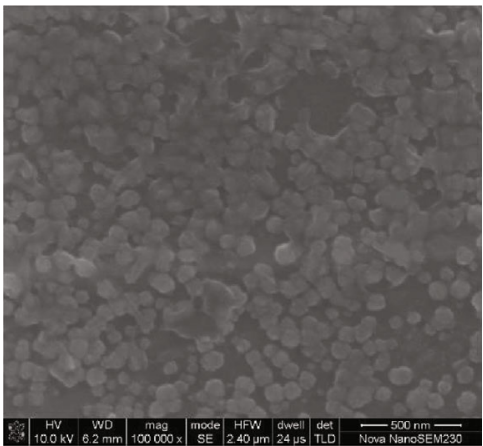

(d)

Figure 6: The size distributions and zeta potential of $\mathrm{CHPN}_{1}$ NPs (A), $\mathrm{CHPN}_{2}$ NPs (B), and $\mathrm{CHPN}_{3}$ NPs (C) after loading drugs MTX (a, b). TEM (c) and SEM (d) image of $\mathrm{CHPN}_{1}$ NPs after loading drugs MTX.

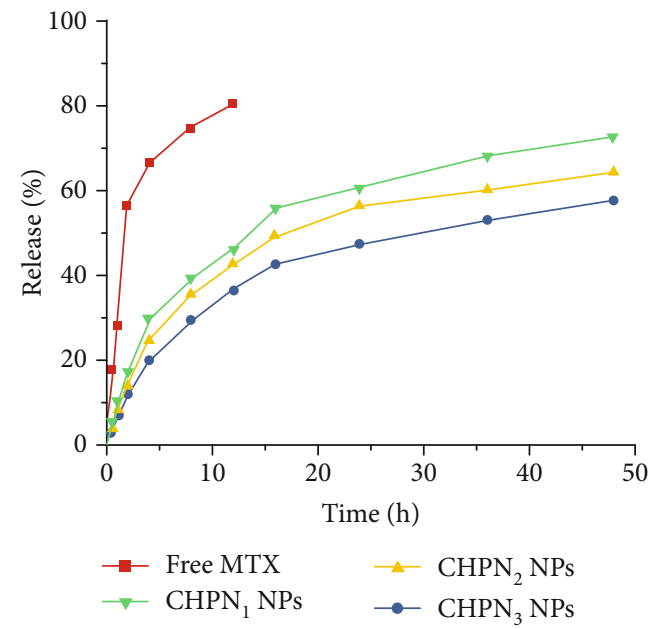

Figure 7: Methotrexate (MTX) release from different NPs or free MTX.

The in vitro cytotoxicity study suggested that the hydrophobic substitution has a great influence on the function of NPs. Controlling the appropriate degree of hydrophobic substitution is of guiding significance for preparing NPs, inhibiting NPs on tumor cells, and improving the curative effect on tumor. The lower hydrophobic substitution NPs had the better inhibitory effect on cancer cells than higher hydrophobic substitution. This finding may be due to the fast release of NP drugs with low hydrophobic substitution, which enter cells in a free form to kill cells, and which is easy to be effectively absorbed by tumor cells $[16,36]$. However, this experiment is still limited to the study at the cell level, and the in vivo behavior has not been studied, because the effectiveness of NPs also depends on their targeting and immune resistance. Targeting is largely related to size, and immune escape is related to size, surface properties, and deformation. In vivo efficacy also needs to consider the toxic side effects and also needs to release better NPs to reduce damage to normal cells. These characteristics are all affected by hydrophobic substitution, so the in vivo situation of NPs with different hydrophobic substitution degree needs further study.

The study suggested the great effect of hydrophobic substitution on NP properties and function. It gives researchers a new instruction to prepare and control the size of NPs and gives us some inspiration to improve drug loading, optimize preparation methods, and improve cytotoxicity.

\section{Conclusion}

All prepared NPs have appropriate evenly distributed particle size, which are inversely proportional to hydrophobicity. 


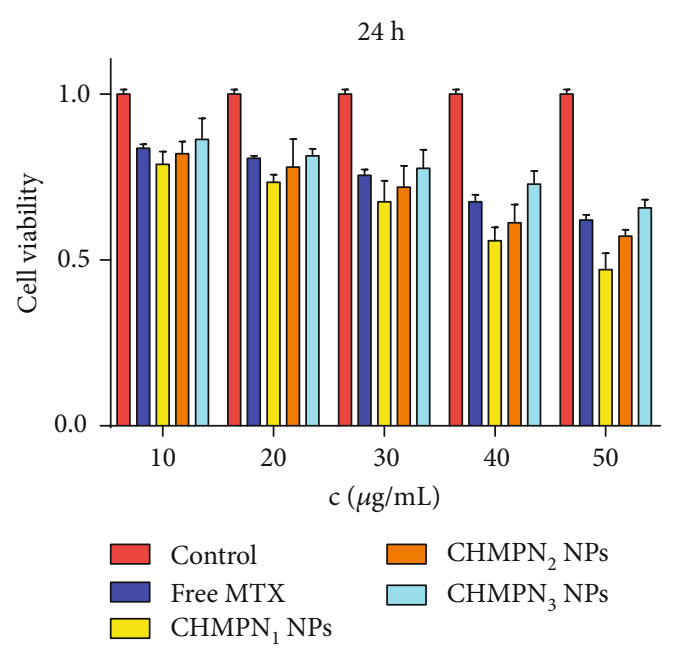

FIGURE 8: Cell viability with different preparations at $24 \mathrm{~h}$.

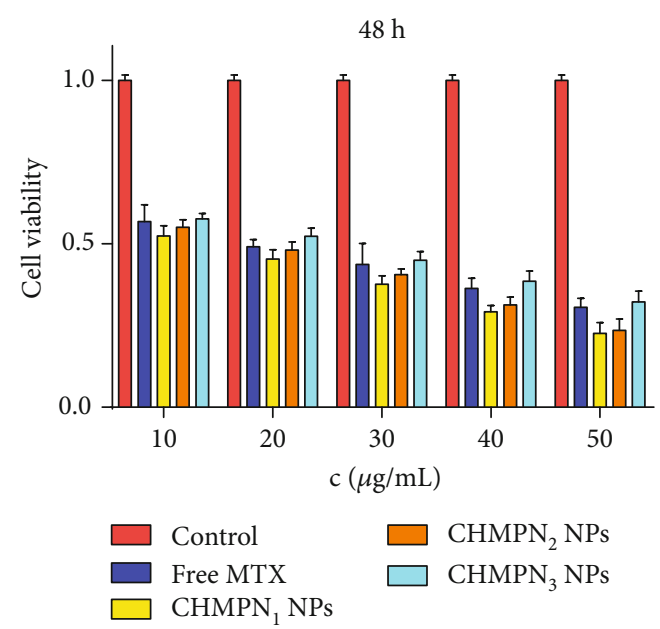

FIGURE 9: Cell viability with different preparations at $48 \mathrm{~h}$.

TABLE 2: $\mathrm{IC}_{50}$ of NPs and free MTX at 24 and $48 \mathrm{~h}$.

\begin{tabular}{lcc}
\hline Sample & \multicolumn{3}{c}{$\mathrm{IC}_{50}(\mu \mathrm{g} / \mathrm{mL})$ at } \\
& $24 \mathrm{~h}$ & $48 \mathrm{~h}$ \\
\hline Free MTX & 101.9 & 17.10 \\
$\mathrm{CHMPN}_{1} \mathrm{NPs}$ & 51.38 & 13.06 \\
$\mathrm{CHMPN}_{2} \mathrm{NPs}$ & 73.70 & 15.18 \\
$\mathrm{CHMPN}_{3} \mathrm{NPs}$ & 132.70 & 19.09 \\
\hline
\end{tabular}

With the increase of hydrophobic, the slow-release effect grows stronger, but the cancer cytotoxicity gets weaker. In this experiment, the hydrophobicity of the polymer has an important influence on particle size, drug loading, and drug release from NPs, and even cytotoxicity. The $\mathrm{CHPN}_{3} \mathrm{NPs}$ with the highest degree of substitution had the smallest size, the highest drug loading, and the lowest cell toxicity. It provides a new mold for research to modify NPs in vitro and has a certain guiding significance for preparing appropriate size nanocarriers with an appropriate hydrophobic substitution degree.

\section{Data Availability}

The data used to support the findings of this study are included within the article.

\section{Conflicts of Interest}

The authors declare that they have no conflicts of interest.

\section{Authors' Contributions}

Huabing Yuan and $\mathrm{Wu}$ Zhong contributed equally to this work.

\section{Acknowledgments}

This project was supported by the Health Commission of Hubei Province (project no. WJ2019H169) to Huabing Yuan and supported by the Hubei Provincial Natural Science Foundation (project no. ZRM S2017000551) and Renming Hospital Guidance Fund of Wuhan University (No. RMYD2018M74) to Wei Hu.

\section{References}

[1] A. C. Jahns, R. G. Haverkamp, and B. H. A. Rehm, "Multifunctional inorganic-binding beads self-assembled inside engineered bacteria," Bioconjugate Chemistry, vol. 19, no. 10, pp. 2072-2080, 2008.

[2] H. S. El-Sawy, A. M. Al-Abd, T. A. Ahmed, K. M. El-Say, and V. P. Torchilin, "Stimuli-responsive nano-architecture drugdelivery systems to solid tumor micromilieu: past, present, and future perspectives," ACS Nano, vol. 12, no. 11, pp. 10636-10664, 2018.

[3] F. Zhang, G. Zhu, O. Jacobson et al., "Transformative nanomedicine of an amphiphilic camptothecin prodrug for long circulation and high tumor uptake in cancer therapy," ACS Nano, vol. 11, no. 9, pp. 8838-8848, 2017.

[4] X. Liu, X. Chen, Y. Li, X. Wang, X. Peng, and W. Zhu, "Preparation of superparamagnetic $\mathrm{Fe}_{3} \mathrm{O}_{4} @$ alginate/chitosan nanospheres for Candida rugosa lipase immobilization and utilization of layer-by-layer assembly to enhance the stability of immobilized lipase," ACS Applied Materials \& Interfaces, vol. 4, no. 10, pp. 5169-5178, 2012.

[5] L. H. Tostanoski and C. M. Jewell, "Engineering self-assembled materials to study and direct immune function," Advanced Drug Delivery Reviews, vol. 114, pp. 60-78, 2017.

[6] T. Akagi, P. Piyapakorn, and M. Akashi, "Formation of unimer nanoparticles by controlling the self-association of hydrophobically modified poly(amino acid)s," Langmuir, vol. 28, no. 11, pp. 5249-5256, 2012.

[7] S. Wang, H. Guo, Y. Li, and X. Li, "Penetration of nanoparticles across a lipid bilayer: effects of particle stiffness and surface hydrophobicity," Nanoscale, vol. 11, no. 9, pp. 40254034, 2019.

[8] H. T. T. Dinh, P. H. L. Tran, W. Duan, B. J. Lee, and T. T. D. Tran, "Nano-sized solid dispersions based on hydrophobichydrophilic conjugates for dissolution enhancement of poorly water-soluble drugs," International Journal of Pharmaceutics, vol. 533, no. 1, pp. 93-98, 2017. 
[9] B. Jothimani, S. Sureshkumar, and B. Venkatachalapathy, "Hydrophobic structural modification of chitosan and its impact on nanoparticle synthesis - a physicochemical study," Carbohydrate Polymers, vol. 173, pp. 714-720, 2017.

[10] X. Ling, J. Tu, J. Wang et al., "Glutathione-responsive prodrug nanoparticles for effective drug delivery and cancer therapy," ACS Nano, vol. 13, no. 1, pp. 357-370, 2019.

[11] R. Liu, W. Xiao, C. Hu, R. Xie, and H. Gao, "Theranostic size-reducible and no donor conjugated gold nanocluster fabricated hyaluronic acid nanoparticle with optimal size for combinational treatment of breast cancer and lung metastasis," Journal of Controlled Release, vol. 278, pp. 127-139, 2018.

[12] F. Shima, T. Akagi, T. Uto, and M. Akashi, "Manipulating the antigen-specific immune response by the hydrophobicity of amphiphilic poly $(\gamma$-glutamic acid $)$ nanoparticles," Biomaterials, vol. 34, no. 37, pp. 9709-9716, 2013.

[13] K. Kettler, C. Giannakou, W. H. de Jong, A. J. Hendriks, and P. Krystek, "Uptake of silver nanoparticles by monocytic THP-1 cells depends on particle size and presence of serum proteins," Journal of Nanoparticle Research, vol. 18, no. 9, article 3595, pp. 286-295, 2016.

[14] Q. Feng, Y. Liu, J. Huang, K. Chen, J. Huang, and K. Xiao, "Uptake, distribution, clearance, and toxicity of iron oxide nanoparticles with different sizes and coatings," Scientific Reports, vol. 8, no. 1, article 2082, 2018.

[15] T. Akagi, K. Watanabe, H. Kim, and M. Akashi, "Stabilization of polyion complex nanoparticles composed of poly(amino acid) using hydrophobic interactions," Langmuir, vol. 26, no. 4, pp. 2406-2413, 2010.

[16] Y. Li, X. Zhang, and D. Cao, "Nanoparticle hardness controls the internalization pathway for drug delivery," Nanoscale, vol. 7, no. 6, pp. 2758-2769, 2015.

[17] N. Wiradharma, Y. W. Tong, and Y. Y. Yang, "Design and evaluation of peptide amphiphiles with different hydrophobic blocks for simultaneous delivery of drugs and genes," Macromolecular Rapid Communications, vol. 31, no. 13, pp. 12121217, 2010.

[18] S. Maiti, S. Manna, J. Shen, A. P. Esser-Kahn, and W. du, "Mitigation of hydrophobicity-induced immunotoxicity by sugar poly(orthoesters)," Journal of the American Chemical Society, vol. 141, no. 11, pp. 4510-4514, 2019.

[19] A. Guerry, S. Cottaz, E. Fleury, J. Bernard, and S. Halila, "Redox-stimuli responsive micelles from DOX-encapsulating polycaprolactone- $g$-chitosan oligosaccharide," Carbohydrate Polymers, vol. 112, pp. 746-752, 2014.

[20] X. Liang, X. Li, X. Yue, and Z. Dai, "Conjugation of porphyrin to nanohybrid cerasomes for photodynamic diagnosis and therapy of cancer," Angewandte Chemie (International Ed. in English), vol. 50, no. 49, pp. 11622-11627, 2011.

[21] R. S. Singh, G. K. Saini, and J. F. Kennedy, "Pullulan: microbial sources, production and applications," Carbohydrate Polymers, vol. 73, no. 4, pp. 515-531, 2008.

[22] H. Li, C. Yu, J. Zhang et al., "pH-sensitive pullulandoxorubicin nanoparticles loaded with 1,1,2-trichlorotrifluoroethane as a novel synergist for high intensity focused ultrasound mediated tumor ablation," International Journal of Pharmaceutics, vol. 556, pp. 226-235, 2019.

[23] X. Tao, S. Jin, D. Wu et al., "Effects of particle hydrophobicity, surface charge, media $\mathrm{pH}$ value and complexation with human serum albumin on drug release behavior of mitoxantrone- loaded pullulan nanoparticles," Nanomaterials, vol. 6, no. 1, p. 2, 2016.

[24] X. Tao, T. Tao, Y. Wen et al., "Novel delivery of mitoxantrone with hydrophobically modified pullulan nanoparticles to inhibit bladder cancer cell and the effect of nano-drug size on inhibition efficiency," Nanoscale Research Letters, vol. 13, no. 1, pp. 345-357, 2018.

[25] S. Vranic, I. Gosens, N. R. Jacobsen et al., "Impact of serum as a dispersion agent for in vitro and in vivo toxicological assessments of $\mathrm{TiO}_{2}$ nanoparticles," Archives of Toxicology, vol. 91, no. 1, pp. 353-363, 2017.

[26] S. Inouye, X. Soberon, T. Franceschini, K. Nakamura, K. Itakura, and M. Inouye, "Role of positive charge on the amino-terminal region of the signal peptide in protein secretion across the membrane," Proceedings of the National Academy of Sciences of the United States of America, vol. 79, no. 11, pp. 3438-3441, 1982.

[27] B. Bennett, P. Langan, L. Coates et al., "Neutron diffraction studies of Escherichia coli dihydrofolate reductase complexed with methotrexate," Proceedings of the National Academy of Sciences of the United States of America, vol. 103, no. 49, pp. 18493-18498, 2006.

[28] Y. Shen, M. Leng, H. Yu et al., "Effect of amphiphilic PCL-PEG nano-micelles on HepG2 cell migration," Macromolecular Bioscience, vol. 15, no. 3, pp. 372-384, 2015.

[29] K. H. Min, K. Park, Y. S. Kim et al., "Hydrophobically modified glycol chitosan nanoparticles-encapsulated camptothecin enhance the drug stability and tumor targeting in cancer therapy," Journal of Controlled Release, vol. 127, no. 3, pp. 208-218, 2008.

[30] W.-H. Wei, X. M. Dong, and C. G. Liu, "In vitro investigation of self-assembled nanoparticles based on hyaluronic aciddeoxycholic acid conjugates for controlled release doxorubicin: effect of degree of substitution of deoxycholic acid," International Journal of Molecular Sciences, vol. 16, no. 12, pp. 7195-7209, 2015.

[31] L. Li, W. S. Xi, Q. Su et al., "Unexpected size effect: the interplay between different-sized nanoparticles in their cellular uptake," Small, vol. 15, no. 38, article 1901687, 2019.

[32] S. Sun, Y. Huang, C. Zhou et al., "Effect of hydrophobicity on nano-bio interactions of zwitterionic luminescent gold nanoparticles at the cellular level," Bioconjugate Chemistry, vol. 29, no. 6, pp. 1841-1846, 2018.

[33] V. Karagkiozaki, P. G. Karagiannidis, N. Kalfagiannis et al., "Novel nanostructured biomaterials: implications for coronary stent thrombosis," International Journal of Nanomedicine, vol. 7, pp. 6063-6076, 2012.

[34] M. A. Raja, M. Arif, C. Feng, S. Zeenat, and C. G. Liu, "Synthesis and evaluation of $\mathrm{pH}$-sensitive, self-assembled chitosanbased nanoparticles as efficient doxorubicin carriers," Journal of Biomaterials Applications, vol. 31, no. 8, pp. 1182-1195, 2017.

[35] X. Tao, Y. Xie, Q. Zhang et al., "Cholesterol-modified amino-pullulan nanoparticles as a drug carrier: comparative study of cholesterol-modified carboxyethyl pullulan and pullulan nanoparticles," Nanomaterials, vol. 6, no. 9, pp. 165-180, 2016.

[36] S. Andreev, D. Reichman, and G. Hummer, "Effect of flexibility on hydrophobic behavior of nanotube water channels," The Journal of Chemical Physics, vol. 123, no. 19, pp. 194502194511, 2005. 


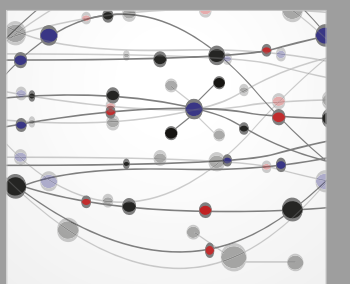

The Scientific World Journal
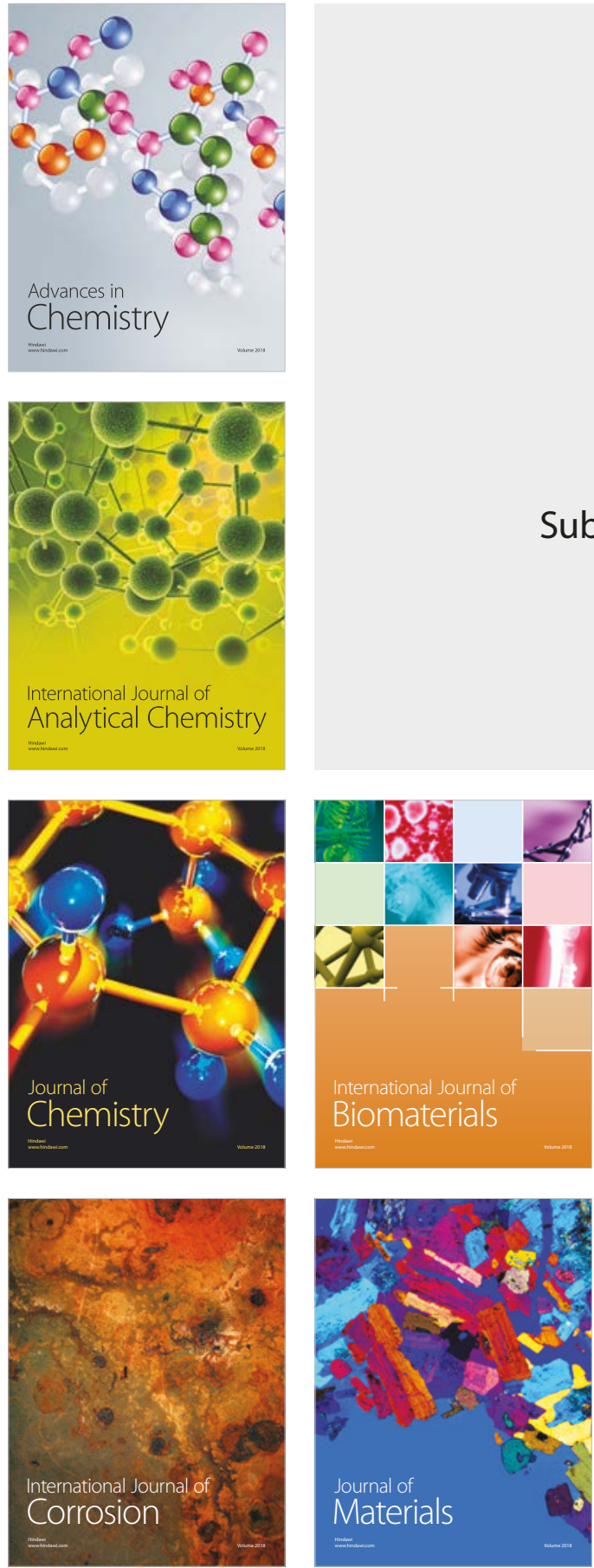

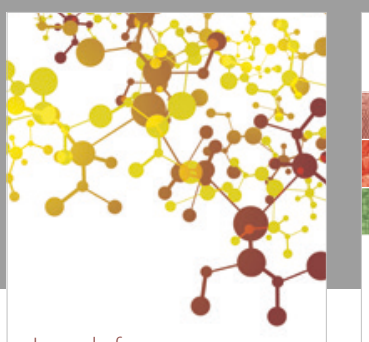

Journal of

Applied Chemistry
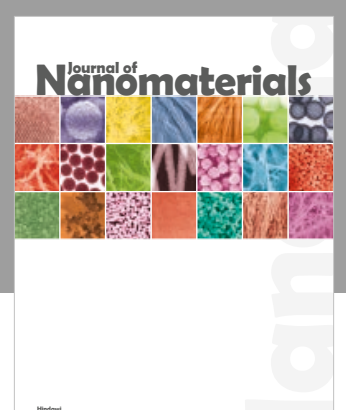

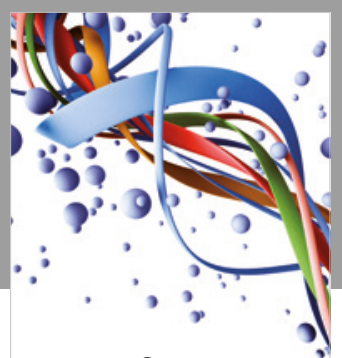

Scientifica

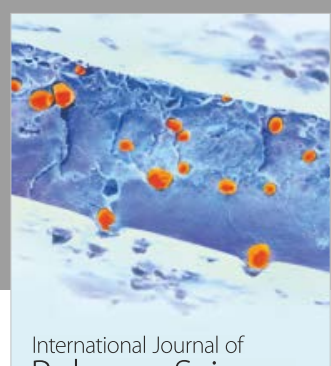

Polymer Science

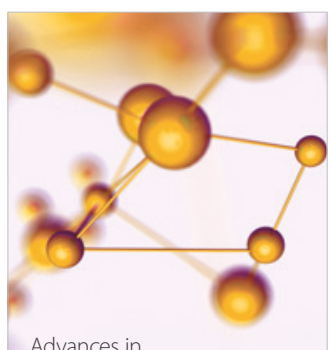

Physical Chemistry
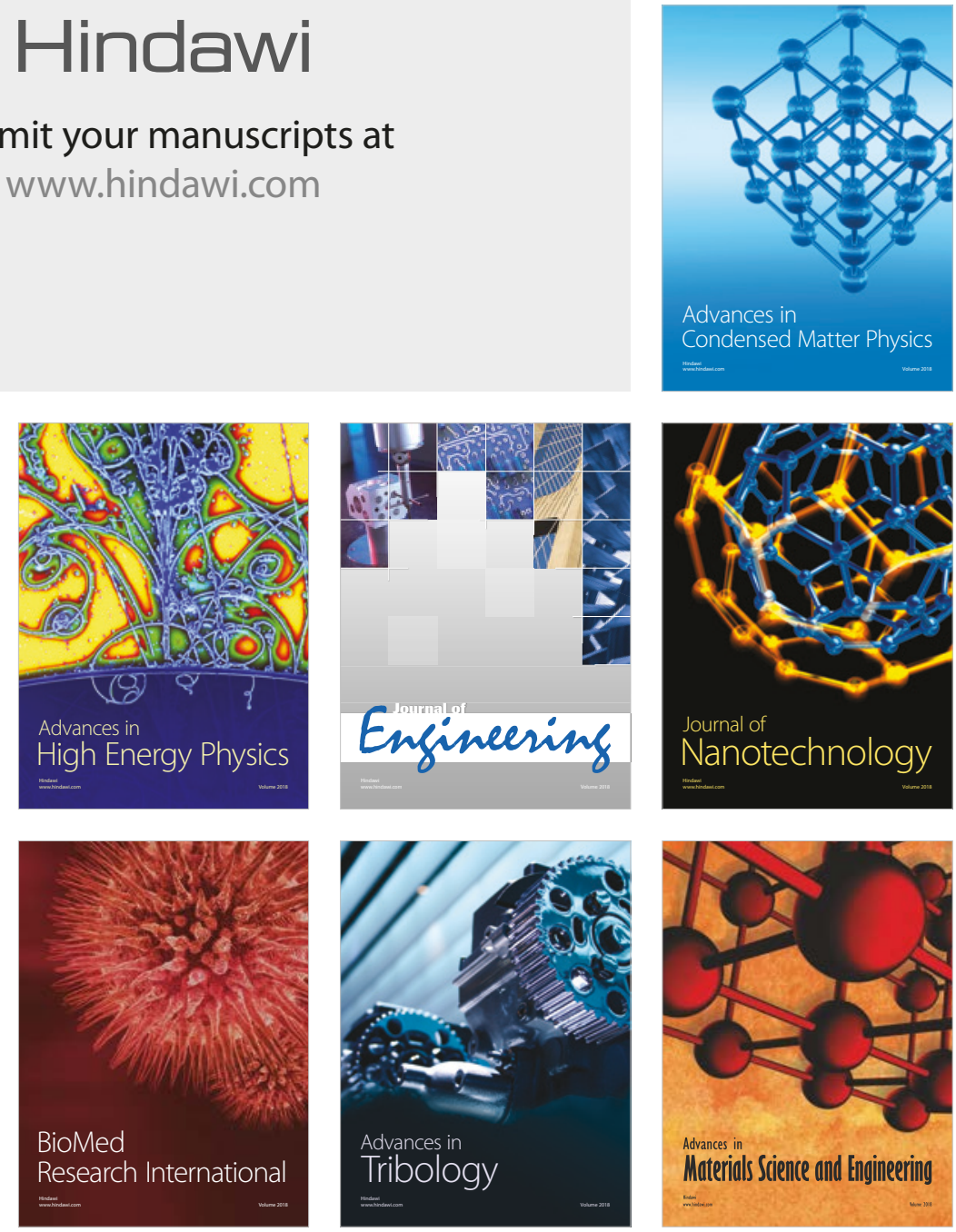